\title{
The Impact of the Implementation of Lunge Exercise with Heel Striking on Fencing
}

\author{
Puji Astuti*, Boyke Mulyana, Pipit Pitriani, Mesianna Simbolon, Alimin Hamzah, Desmi Sartika \\ School of Postgraduate Studies \\ Universitas Pendidikan Indonesia \\ Bandung,Indonesia \\ *pujias@upi.edu
}

\begin{abstract}
This paper is a scientific study of a review paper about fencing. The development of fencing sports, the more modern style game of fencing with a pattern of game, are fast and explosive. To support fast and effective movements, appropriate techniques and body movements are needed that can support fencing movements. The heel contact when carrying out an attack is a traditional technique, and the technique is not effective in modern fencing so far. Recently, Modern fencing uses footballs that support the player to move quickly. In addition to the effectiveness and speed of movement, this first ball footwear minimizes pressure on the foot because the movement bounces and is not charged to just one place, but it is distributed among ankle knee and hip joints. Meanwhile, the high use of heel contact can cause an excessive injury resulted in bone fatigue. This happens because the pressure received is charged at one point, the heel itself. Therefore, it has an impact on the knees and hips. This paper presents scientific knowledge about the impact of heel attack training on the occurrence of injuries in fencing. Coaches and athletes should be able to be selective in training and carrying out techniques in the correct manner to minimize the occurrence of injuries as well as to support fast and effective movements when playing fencing.
\end{abstract}

Keywords: fencing, footwork, lunge, injury

\section{INTRODUCTION}

Fencing is a sport that was taken and competed at the first Olympics in Athens in 1896 [1], where this fencing is a battle sport with ancient traditions of war or duel [2]. With the development of the era, the sport of fencing continues to grow both regarding fencing recreation itself as well as the development of fencing patterns. Modern fencing is now a fastpaced and explosive game in motion [2].

This sport involves three skills: weapons work, footwork, and tactics. A fencing athlete needs a constant range of movements in forward, backward, and attacking during competitive matches [1]. The movement of the foot in the first contact fencing that touches the floor is part of the heel [2], explained in Turner \& Harmenberg [2]:

To go forward, lifting the tip of the foot stepping foot you and forward (about one foot), no more than $15 \mathrm{~cm}$ [3], landed on the heel and place flat, then lift foot behind and move to distance the same to the forward, backward just the opposite and foot forward push with the heel.
From a young age, fencers drilled forward, backward movements in fencing using shoe heels [2]. Described in Sinclair and Bottoms to advance, lift your leading toe and step forward. [4].

About one foot in length [5], no more than $15 \mathrm{~cm}$ deep, land on the heel and place the foot flat, then lift the back leg and move it the same distance forward, backward is just the opposite and the foot is pushed with the heel.

While the heel contact technique first is a traditional technique. Modern fencing is now a fast-paced and explosive game in motion [2]. To play fast and explosively requires good motion techniques, so that the resulting motion is more efficient, then the heel contact with the floor is less efficient first, because the load when the heel touches the floor is heavier so it is difficult to move the body faster and explosive.

In the literature which says the main principles that are fundamental to footballs are not allowed on fencing movements. However, in martial arts sports such as boxing and taekwondo, where the imposition of footballs contributes greatly in every movement [2]. Continuous bouncing fencing movements must be supported by elastic energy in the Achilles tendon to be ready to move forward, backward, faster with energy using footballs. Footballs are used in three different differences: (1) " just in case " position, i.e. bouncing instead of stationary TCAs, (2) shorter movements by bouncing instead of TCAs replacing or cancelling user TCAs and (3) in longer movements use push-offs with footballs (with or without a bouncing start), making progress and retreat (and lunges) longer and faster.

In fencing every movement is done repeatedly, both punctures, steps, and attacks. Most injuries arising from fencing are often performed [6], especially the lower extremity which has a high chance of injury. With the increased mobility in playing fencing the use of heels when landing in fencing puts more strain on the lower body, this triggers injuries to athlete.

The burden received by the body from the movement of both forward, backward and attacking is very large, so it can cause injury to that part. Previous research said that in sports fencing the dominant occurrence of injury is part of lower extremity. Injury data report the hamstrings as a muscle group 
for fencers who come in direct heel contact, because they cannot back down since their weight will be centered on the back foot. The bouncing fencer won't have a problem because they won't change the body into a certain leg [2]. Each sport has the possibility of injury, both sports that have body contact or not. Previous research has revealed that the lower extremity is the most frequent location for fencing injuries $[8,10,11]$. Acute and overload injuries are a problem for elite and nonelite fencers and higher injury rates were reported for national and international competitions [1,11]. In other research, a 1-year study of competitions in the Lombard region of Italy3 involving 1365 fencers noted only three injuries (forearm contusion, knee sprain, and aggravation of an existing metacarpal fracture) that resulted in athlete withdrawal from competition [12].

In a 5-year survey by the USFA [12], 184 cases of time-loss injuries were recorded for 610 exposures with an overall $30.0 \%$ of injury rate. Approximately 52\% of all reportable injuries were first or second-degree strains and sprains. Lower limb is most susceptible to injuries. The injury rates were $19.6 \%$, $15.2 \%$, and $13.0 \%$ respectively for the knee, thigh, and ankle. These injuries also carry a high risk of chronic morbidity, predominantly achillodynia and patellofemoral pain $[13,14]$. The possibility of injury to a fencing athlete is caused fencers' feet are repeatedly exposed to large transient impact shock, especially during sudden forward thrusts, increasing the risk of lower limb injuries. And this is compounded if the athlete performs with the wrong technique or imposition.

\section{CONCLUSION}

Recent research on modern fencing that demands a fast and explosive game cannot be supported by the technique of contact with the heel of the foot, because the burden that is received by the foot through wearing the heel of the foot can result in injury to the athlete. The opportunity for injury in the lower body in fencing athletes due to continuous attacks is also quite large, if coupled with the wrong movement patterns and burdens the muscles, the chances of fencing athletes getting injured are greater. Injuries that occur are usually found in the knee, gastrocnemious muscle sprain and hamstring etc. To reduce the impact of the injury, it is necessary to practice contact with footballs on attacking movements in fencing.

\section{REFERENCES}

[1] C. Trautmann, N. Martinelli, and D. Rosenbaum, "Foot loading characteristics during three fencing-specific movements," Journal of sports sciences, vol. 29(15), pp.1585-1592, 2011.

[2] A.N. Turner and J. Harmenberg,"Why fencers should bounce: A new method of movement to engage the stretch-shortening cycle," International Journal of Sports Science and Coaching, vol. 13(3), pp. 452-460, 2018.

[3] A. Simmonds, and E. Morton, "Fencing to win," London: The Sportmans Press, 1997.

[4] J. Sinclair, L. Bottoms, P.J. Taylor, and K. Mahmood, "Effects of shoes on kinetics and kinematics of the squash forward lunge in male players," Kinesiology: International journal of fundamental and applied kinesiology, vol. 49(2), pp. 178-184, 2017.

[5] M.R Garret, E.G. Kaidanov and G.A. Pezza, "Foil, Saber, and Épée Fencing: Skills, Safety, Operations, and Responsibilities," Penn State Press, 1994 thereby shifting body weight to the front foot. Then the opponent can lunge and attack, which will be very challenging 
[11] E.D. Zemper, and P. Harmer, "Fencing. Epidemiology of Sports Injuries," Champaign, IL: Human Kinetics, pp.186-195, 1996.

[12] P.A. Harmer, "Incidence and characteristics of time-loss injuries in competitive fencing: a prospective, 5-year study of national competitions," Clinical Journal of Sport Medicine, vol. 18(2), pp. 137 142, 2008.

[13] A. Reinberg, S. Proux, J.P. Bartal, F. Lévi, and A. Bicakova-rocher, "Circadian rhythms in competitive sabre fencers: internal desynchronization and performance," Chronobiology international, vol. 2(3), pp.195-201, 1985.

[14] A.I. Murgu, R. Buschbacher, "Fencing," Physical medicine and rehabilitation clinics of North America, vol. 17(3), pp. 725-36, 2006

[10] C. Carter, J. Heil, and E. Zemper, "What hurts and why-data from the 1992 USFA Fencing Injury Survey shows some common culprits," American Fencing, vol. 43(3), pp. 16-17, 1993. 